\title{
ROMANCES GRÁFICOS COMO LEITURA ESCOLAR: WATCHMEN E A FICÇÃO AMPARADA NA HISTÓRIA
}

\author{
João Cláudio Arendt ${ }^{1}$ \\ Roberto Rossi Menegotto ${ }^{2}$
}

\begin{abstract}
Resumo: No presente artigo, propomos a inserção de romances gráficos na sala de aula, especialmente nas disciplinas de literatura e língua portuguesa. Esse recente gênero textual, derivado das Histórias em Quadrinhos (HQs) tradicionais, surpreende, muitas vezes, por sua qualidade gráfica e temática. No caso específico de Watchmen, de Alan Moore, realizamos uma breve análise de fatos históricos nela presentes. Partimos de uma rápida definição de romance gráfico, passamos por dados biográficos do autor e por dados do contexto geral da obra e desembocamos na análise de duas capas de jornal com manchetes reais presentes em Watchmen, com o intuito de verificarmos a relação entre a graphic novele eventos históricos da humanidade.
\end{abstract}

Palavras-chave: Leitura escolar. Watchmen. Histórias em quadrinhos. Fatos históricos.

\section{GRAPHIC NOVELS LIKE SCHOOL READING: WATCHMEN AND FICTION SUPPORTED IN HISTORY}

\begin{abstract}
In the present article, we propose the applicability of graphic novels at school, especially at literature and portuguese classes. This textual genre, derived from traditional comic books, surprises, many times, with its themes and graphical quality. With Watchmen, by Alan Moore, we briefly analyze the historical facts present in it. The starting point is a definition of graphic novels. From there, we expose biographic facts about the author and the general context of the book. Then, we analyze two newspaper front pages with real headlines, to verify the connection between the graphic novel and historical events.
\end{abstract}

Keywords: School reading. Watchmen. Comic books. Historical facts.

\footnotetext{
${ }^{1}$ Editor chefe de Antares (Letras e Humanidades), coordenador do Programa de Doutorado em Letras Associação Ampla UCS-Uniritter do Programa de Pós-graduação em Letras, Cultura e Regionalidade da UCS. Endereço eletrônico: jcarendt@ucs.br.

${ }^{2}$ Mestrando no Programa de Pós-graduação em Letras, Cultura e Regionalidade - PPGLET/UCS da Universidade de Caxias do Sul. Graduado em Comunicação Social - Publicidade e Propaganda e Comunicação Social - Jornalismo pela Universidade de Caxias do Sul. Email: roberto.rmenegotto@gmail.com.
} 


\section{Introdução}

Considerando as transformações por que tem passado o ensino de literatura e de língua portuguesa nas escolas brasileiras, nas últimas décadas, com significativos avanços metodológicos, teóricos, materiais e textuais, não seria justo que ficassem de fora da sala de aula as novas linguagens, especialmente as Histórias em Quadrinhos (HQs), as charges, as tirinhas e os romances gráficos, bem como as produções resultantes de traduções intersemióticas. Obviamente, nada substitui a leitura de um determinado texto literário, nem mesmo sua versão em filme, seu resumo ou resenha, já que cada gênero textual tem suas particularidades e desempenha função específica.

Entretanto, é possível ampliar o escopo que constitui o objeto de estudos da disciplina de literatura, fragilizando a hegemonia do texto literário convencional. Se se tomam, por exemplo, o romance Dom casmurro (1899), de Machado de Assis, a história em quadrinhos Dom Casmurro (2011), de José Aguiar e Wellington Srbek, e o filme Dom (2003), de Moacyr Góes, é necessário ter presente que cada um deles utiliza um código semiótico próprio e, por isso, um não substitui o outro. Não seria pertinente, também, a utilização de certos rótulos, como versão e adaptação, para os referidos textos. Cada um deles demandará formas diferentes de leitura, fruição e interpretação, já que se trata de suportes e gêneros distintos. Em outros termos, sugere-se que o filme e a HQ não sejam utilizados de modo simplista para compreender o texto de Machado de Assis, mas sim para ampliar o universo de referências literárias e não literárias do estudante.

Além disso, como será observado a seguir, mesmo HQs que não constituem traduções intersemióticas de outros textos podem ser integradas às aulas de literatura e de língua portuguesa. A análise de recursos visuais, textuais e narrativos, bem como de aspectos sociais, políticos e históricos constitui uma possibilidade interessante de abordagem interdisciplinar que pode enriquecer substancialmente o conjunto de referências culturais do leitor em formação. 


\section{Watchmen, HQs e representação da história}

Há 30 anos, o universo das histórias em quadrinhos sofreu uma revolução. Entre setembro de 1986 e outubro de 1987, o mundo viu surgir a publicação de Watchmen, um romance gráfico diferente de tudo o que havia sido produzido até então. Abordando temas ancorados na realidade mundial e, principalmente norte-americana, a história escrita por Alan Moore e ilustrada por Dave Gibbons constitui um marco literário, considerada por muitos uma das publicações mais importantes da história. Watchmen transformou o mercado editorial das HQs e tornou-se inspiração para inúmeras histórias lançadas nos anos seguintes e que, no seu trigésimo aniversário, continua sendo referência.

Com o fim da Guerra do Vietnã, em 1975, o mercado de quadrinhos dos Estados Unidos sofreu um declínio nas vendas, em vista de sua derrota e da consternação generalizada que tomou o país. Para Hiron Cardoso Goida e André Kleinert (2014, p. 12), “depois da Guerra do Vietnã, do fim do sonho norte-americano, haviam caído por terra o moralismo e outras conversas fiadas em torno da Pátria e do patriotismo." Enquanto isso, na Europa, proliferavam as narrativas inovadoras. Ainda, conforme Goida e Kleinert (2014), na década de 1960, no Velho Continente, ocorreu o surgimento dos romances em quadrinhos, histórias dedicadas a um público maior de 15 anos. Esse gênero inspirou o mercado norte-americano, que precisava de uma retomada nas vendas. Deu certo. Editoras como Marvel Comics e DC Comics reagiram, e seus super-heróis ganharam novo fôlego com o lançamento de formatos inovadores, como as minisséries, e o surgimento de prodigiosos autores. Um deles foi Alan Moore, ganhador de inúmeros prêmios de quadrinhos, como o Jack Kirby Award e o Eisner Award.

Nascido na Inglaterra, Alan Moore começou seu trabalho com quadrinhos no fim dos anos 1970, mas foi na década seguinte que realmente começou a se destacar. De acordo com Goida e Kleinert (2014), em seus primeiros anos, ele criou a minissérie $V$ de Vingança, o personagem John Constantine e roteirizou a história da série Monstro do Pântano e duas das principais histórias do Superman - Para o homem que tem tudo e $O$ que aconteceu com o homem de aço?, além da célebre e polêmica Batman - a 
piada mortal. Porém, seu maior feito e uma das maiores realizações no mundo das histórias em quadrinhos é indiscutivelmente a minissérie Watchmen. Moore, conhecido por sua postura radical de esquerda, criou uma série para, além de abordar diversos problemas sociais e políticos, criticar o mercado editorial de histórias em quadrinhos. Conforme Dan Mazur e Alexander Danner (2014, p. 176), “A grande ironia de Watchmen é que Moore reacendeu a empolgação de muitos leitores para o gênero super-herói exatamente com o trabalho que ele esperava que fosse seu epitáfio."

Watchmen passa-se em uma realidade alternativa do planeta Terra. Nela, o grupo de heróis vigilantes Crimebusters, formado em 1960, é extinto em 1977, após a instauração de uma lei que proíbe a atuação de vigilantes mascarados, em razão de greves da polícia e protestos da população por sua atuação ilegal e uso exagerado de força. Anos após o fim do grupo, uma figura misteriosa tenta eliminá-los, um a um. Nessa versão dos EUA, o país venceu a Guerra do Vietnã graças à interferência de Dr. Manhattan, um super-humano onisciente nascido de um acidente com radiação. Com os poderes do superherói e seu conhecimento absoluto do funcionamento dos átomos, o mundo viu um grande avanço tecnológico na indústria e em diversos setores das ciências. Um dos campos mais afetados foi o militar, o que levou à produção em massa de ogivas nucleares em nações como EUA e Rússia, gerando pânico de uma guerra iminente, em razão das tensões entre os dois países por disputas no Afeganistão.

O trabalho de Moore é impecável, traçando perfis psicológicos de cada um dos heróis e da sociedade norte-americana. Apesar de ser uma versão alternativa do planeta Terra, a história é toda influenciada por eventos históricos reais. Na $\mathrm{HQ}$, o fator desencadeador para o surgimento do primeiro herói mascarado - Justiça Encapuzada - em outubro de 1938, foi o lançamento e a influência, em maio do mesmo ano, da edição número 1 da Action Comics. Foi nessa revista - lançada também no mundo "real" - que ocorreu a primeira aparição do Super-Homem. Conforme Sean Howe (2013), ao estrear na capa da primeira revista, o personagem foi um sucesso instantâneo. Na sétima edição, a editora Detective Comics já vendia mais de meio milhão de exemplares. Segundo Howe: 
O personagem era uma mistureba de tudo o que as crianças gostavam - heróis dos pulps, ficção científica, mitos da Antiguidade - em um só esplêndido pacote nas cores primárias. O “campeão dos oprimidos, a maravilha corpórea que jurou dedicar sua vida a auxiliar os necessitados", enfrentava magnatas gananciosos e políticos corruptos, sempre pregando o reformismo social. Mas Superman era mais do que um símbolo. Sua identidade secreta, o pateta Clark Kent, dava até aos leitores mais solitários um colega renegado com quem se identificar (HOWE, 2013, p. 20).

Após o surgimento de Justiça Encapuzada, outros heróis apareceram no universo de Watchmen e formaram, em 1940, o primeiro grupo de vigilantes dedicados a lutar pela justiça. Eles se autointitulavam HomensMinuto (Minutemen, no original), tal como, segundo Antonio Pedro Tota (2009), os colonos americanos que formaram milícias para combater os ingleses, no século XVIII. Com o fim da equipe original de heróis, decorrido em razão de disputas internas e problemas com o relações públicas do grupo, a luta do bem contra o mal coube a uma nova geração de heróis: os Crimebusters. De acordo Dan Mazur e Alexander Danner (2014):

[Alan Moore] Combinou aspectos de histórias em quadrinhos de super-heróis com o mistério de assassinato, suspense psicológico e comentários sobre a natureza da própria autoridade, precisamente estruturados em camadas de imagens simbólicas, todos encenados por arquétipos de super-heróis levados a seus extremos lógicos: o homem-deus sem emoções, o acadêmico/atleta, a encarnação da perfeição humana, o vigilante urbano hipócrita e perigoso, o tímido e indeciso benfeitor (MAZUR; DANNER, 2014, p. 176).

Os heróis com falhas graves, o clima de mistério, os comentários do autor a respeito da natureza humana e a ambientação em um cenário similar ao "real", que temia a entrada dos EUA em uma guerra nuclear com a Rússia em razão da interferência no Afeganistão, serviram para que Watchmen fosse uma representação verossímil da época e, instantaneamente, aclamado por 
público e crítica. Moore conseguiu um diálogo preciso com o público, sabendo compreender o Zeitgeist daquela geração. Conforme Will Eisner (1985):

\begin{abstract}
As histórias em quadrinhos comunicam numa "linguagem" que se vale da experiência visual comum ao criador e ao público. Pode-se esperar dos leitores modernos uma compreensão fácil da mistura imagempalavra e da tradicional decodificação do texto. A história em quadrinhos pode ser chamada "leitura" num sentido mais amplo que o comumente aplicado ao termo (EISNER, 1985, p. 6).
\end{abstract}

Moore parece ser um especialista em entender as características daquela década. A HQ demanda do leitor que internalize as mesmas questões abordadas pela obra e, ao mesmo tempo, tente respondê-las incessantemente. Para Moacy Cirne (2000), o quesito fundamental em um romance gráfico é o de abrir espaço para a continuação daquela história na mente do leitor. Não basta que as ilustrações contenham uma história, elas precisam ir além. Para ele:

[...] é necessário que, no interior da imagem, haja espaço para reflexão, para a crítica, para o questionamento. E para o sonho, para o delírio, para o imaginário em transe, quando for o caso. Assim, através da imagem (e da palavra, claro), poderemos dizer com todas as letras: questionamos, logo pensamos; pensamos, logo questionamos. E, de uma forma ou outra, imaginamos a partir da imagem (CIRNE, 2000, p. 135).

Watchmen flutua onde outras histórias em quadrinhos naufragam. Para cada pedaço de informação narrada ou ilustrada, há uma justificativa. Mais que isso: essas justificativas são instigantes e de caráter informativo, quando comparadas com o status quo das décadas descritas. O super-humano Dr. Manhattan, com sua alcunha de herói em alusão clara ao Projeto Manhattan, é considerado um ser perfeito pelos habitantes daquele planeta Terra alternativo. Porém, é vazio de sentimentos, incapaz de compreender a vastidão das emoções humanas, pois enxerga todos como engrenagens de um relógio e, quando confrontado por supostamente causar câncer nas pessoas 
com quem teve convívio prolongado, sente-se contrariado e decide ir para Marte viver isolado. A referência às pesquisas da metade do século XX com elementos radioativos e às bombas atômicas é clara, além do julgamento que Moore faz da falta de compaixão dos pesquisadores e do seu distanciamento das emoções. Para Jan Mukarovsky (1988), toda obra artística contém cargas de informação, além da estética:

A obra poética, como qualquer outra manifestação linguística, pode, bem entendido, conter todos os outros tipos de valores: por exemplo, os valores existenciais (a realidade ou a irrealidade dos fatos), os valores intelectuais (a exatidão ou inexatidão, a originalidade ou não originalidade das ideias), os valores éticos, sociais, religiosos, etc. (MUKAROVSKY, 1988, p. 169).

A complexidade presente em Watchmen e a carga de informações presentes na obra fazem com que seja uma tarefa árdua encontrar pontos isolados de ligação com a realidade. A HQ inteira é um paralelo intrínseco e quase indissociável de uma geração afetada pela Segunda Guerra Mundial, Projeto Manhattan, Guerra do Vietnã, Corrida Espacial, Guerra Fria, Crise dos Mísseis de Cuba, debates sobre autoridade e responsabilidade, sexualidade etc.

Os principais fatos que marcaram o século $\mathrm{XX}$ podem ser encontrados ao longo das 394 páginas da obra. O próprio nome Watchmen faz um trocadilho irônico. O verbo em inglês to watch pode ser traduzido para o português como assistir ou vigiar, enquanto o substantivo watch pode ser entendido como relógio. Logo, percebe-se que, enquanto o grupo de heróis vigia a população para o seu bem, a população aguarda assustada a chegada da meia noite no Relógio do Juízo Final ${ }^{3}$. Segundo Mazur e Danner (2014, p. 176), “[...] a atenção que dá ao elemento visual é evidente em cada quadro de ilustrações de Dave Gibbons, pois assimetrias e motivos visuais (especialmente relógios e formas de relógios) conectam todos os momentos da

\footnotetext{
${ }^{3}$ O Relógio do Juízo Final foi criado em 1947, na Universidade de Chicago. Ele representa a metáfora da proximidade humana em minutos para a meia-noite. Nesse contexto, meia-noite representa a tota obliteração do planeta em decorrência de uma guerra nuclear. Fonte: Bulletin of the Atomic Scientists. Disponível em: < http://thebulletin.org/timeline>. Acesso em: 25 nov. 2016.
} 
história, do início ao fim." Segundo Mukarovsky (1988), é comum objetos dotados de função estética utilizarem fatos não estéticos como fonte de inspiração em sua criação. No entanto, para que isso ocorra, depende-se de uma consciência coletiva que fará ligação com a realidade, tornando a obra válida como referência. Para o autor:

\begin{abstract}
A esfera do estético evolui, portanto, no seu conjunto. Além disso encontra-se em permanente relação com aqueles setores da realidade que, num dado momento, não são, em absoluto, portadores de função estética. Uma tal unidade e integridade só são possíveis na base de uma consciência coletiva que estabelece as relações entre as coisas (MUKAROVSKY, 1988, p. 35).
\end{abstract}

Como a obra não é narrada em ordem cronológica, Moore e Gibbons auxiliam os leitores a se situarem na trama por meio da utilização de capas de jornais fictícios com manchetes reais pertinentes à época ambientada. Essas páginas de jornal geralmente estão dispostas em primeiro plano no quadrinho, fazendo com que o tempo-espaço fique em destaque. Deve-se atentar, porém, para a presença de manchetes fictícias que dizem respeito somente àquela Terra alternativa. Will Eisner (1985) alerta para a necessidade de percepção por parte do leitor:

\begin{abstract}
A configuração geral da revista de quadrinhos apresenta uma sobreposição de palavra e imagem, e, assim, é preciso que o leitor exerça as suas habilidades interpretativas visuais e verbais. As regências da arte (por exemplo, perspectiva, simetria, pincelada) e as regências da literatura (por exemplo, gramática, enredo, sintaxe) superpõem-se mutuamente. A leitura da revista em quadrinhos é um ato de percepção estética e de esforço intelectual (EISNER, 1985, p. 8).
\end{abstract}

Entre todos os recursos narrativos utilizados por Moore e recursos gráficos de Gibbons, as letras garrafais destacadas nesses encartes são os 
paralelos mais explícitos que Watchmen traça com o contexto histórico representado. Para dar clareza aos aspectos mencionados, serão analisadas, a seguir, duas capas de jornais com notícias reais presentes na obra. Ao contrário da narrativa nos quadrinhos, os jornais serão apresentados na ordem cronológica em que os fatos históricos ocorreram.

\section{Watchmen e a inspiração em fatos históricos}

O capítulo 4 de Watchmen é dedicado a narrar a história de origem do super-humano Dr. Manhattan. No dia 7 de agosto de 1945, o aprendiz de relojoeiro Jonathan Osterman pratica o ofício, quando seu pai entra na sala com um jornal em mãos. A ilustração deixa claro que ele está assustado e empolgado ao mesmo tempo. O homem manda Jonathan parar de trabalhar no relógio, para que leia a notícia. No quadrinho superior direito, pode-se ler claramente que uma bomba atômica foi explodida em Hiroshima, no Japão, levando a cidade inteira a desaparecer. Ao fundo, vê-se um calendário com a data mencionada. O pai de Jonathan recolhe as peças de relógio em que o filho trabalhava e as joga fora, pela escada de incêndio, mesmo ouvindo protestos para que não o faça. O pai argumenta que ele deve parar de trabalhar em coisas obsoletas, pois o futuro será dominado pelas ciências atômicas. No último quadrinho, há um salto temporal. Jonathan explica que, três anos após o ocorrido, em 1948, ele chega à Universidade de Princeton para estudar. Em 1958, ele consegue seu Ph.D. em Física Atômica. Observe-se: 

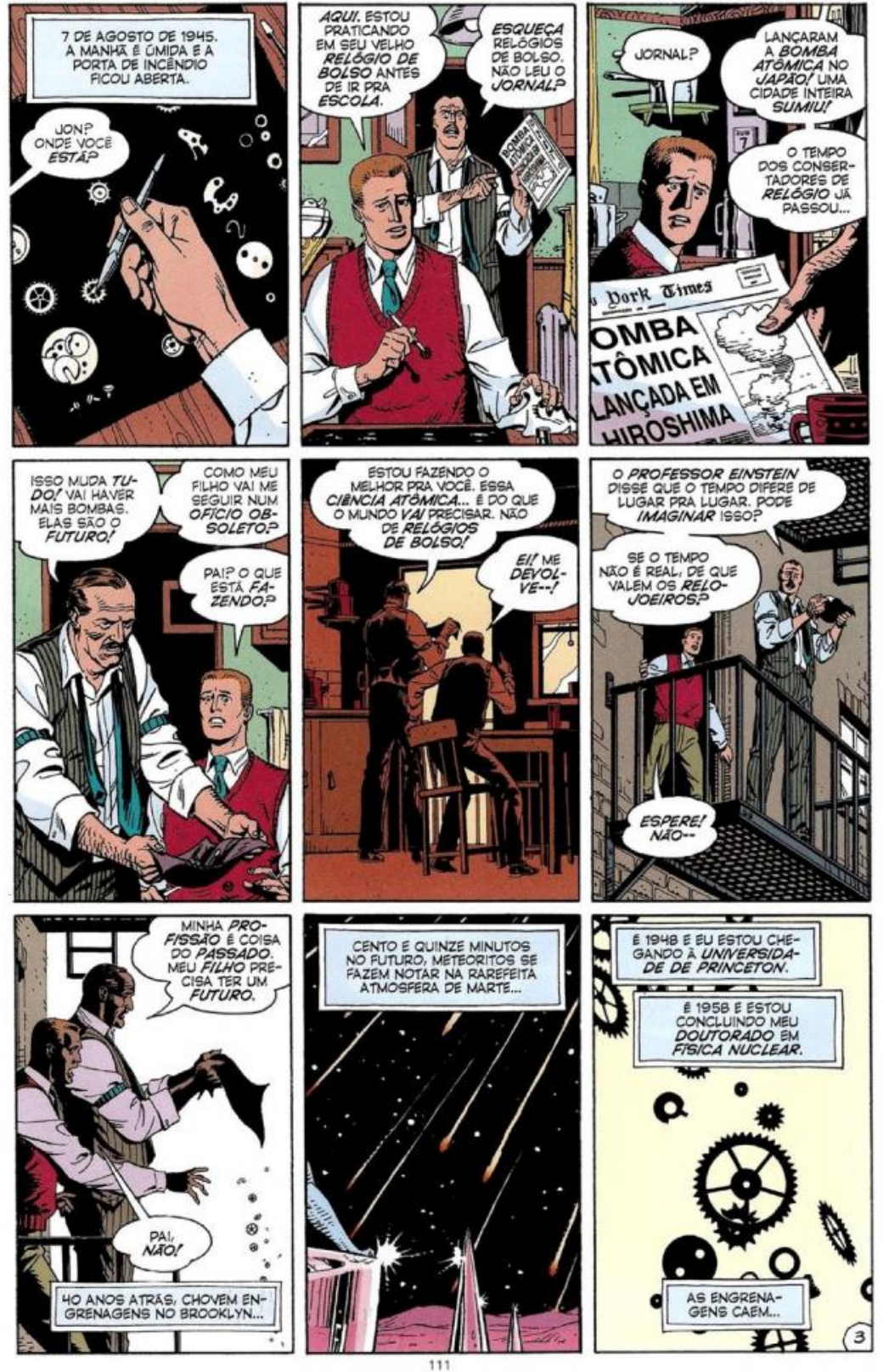

Fonte: MOORE, Alan. Watchmen. São Paulo: Vertigo, 2008.

O destino do futuro Dr. Manhattan é afetado diretamente pelo advento da bomba atômica e seu uso na cidade de Hiroshima, em 6 de agosto de 1945. A explosão artefato culminou na rendição do Japão poucos dias depois 
e, com isso, a Segunda Guerra Mundial chegou ao fim. Segundo Jan Mukarovsky (1988):

[Uma obra de arte] falará tal como uma manifestação puramente comunicativa - de um acontecimento em tal ou tal parte, em tal ou tal época, em tais ou tais circunstâncias e com tais ou tais personagens; mas haverá uma diferença: enquanto concebemos determinada manifestação como comunicação, o importante para nós é a relação entre a informação e a realidade a que ela se refere (MUKAROVSKY, 1988, p. 72).

A imagem a seguir mostra uma figura caminhando sob chuva, em 1985. Calmamente, essa pessoa encontra um jornal jogado próximo a uma lata de lixo. A capa traz a manchete sobre a invasão russa ao Afeganistão. Essa notícia, em Watchmen, é muito significativa por diversas razões. Em 1985, os russos intensificaram a ofensiva ao Afeganistão, contando com mais de cem mil soldados no país. Os Estados Unidos, apesar de não estarem diretamente envolvidos na guerra, davam suporte aos islâmicos, com armas e treinamento para combate. Enquanto isso, a população americana temia uma retaliação por parte da União Soviética, podendo chegar a uma guerra nuclear entre os dois países.

Em Watchmen, a ofensiva russa ocorre quando Dr. Manhattan abandona o planeta Terra e vai para Marte. Com a perda do trunfo bélico americano, os soviéticos entendem que aquele é o momento certo para intensificar os ataques ao Afeganistão. Nos quadrinhos, é importante notar, também, o reflexo na poça d'água de um letreiro de bar. A predominância de vermelho e amarelo - cores da bandeira da União Soviética - combinada com ossos cruzados, símbolo de perigo ou toxicidade, alertam para o perigo iminente. Nas páginas subsequentes da narrativa, vê-se que o homem que, tranquilamente, ignora a notícia sobre a guerra, é um antigo inimigo dos Watchmen, que atualmente sofre de câncer em estágio terminal. Isso explica sua falta de interesse e preocupação com uma possível guerra nuclear. Sua morte está próxima, e as longas sessões de quimioterapia não serviram para que fosse curado. 


\section{Pontos de \\ Interrogagão}
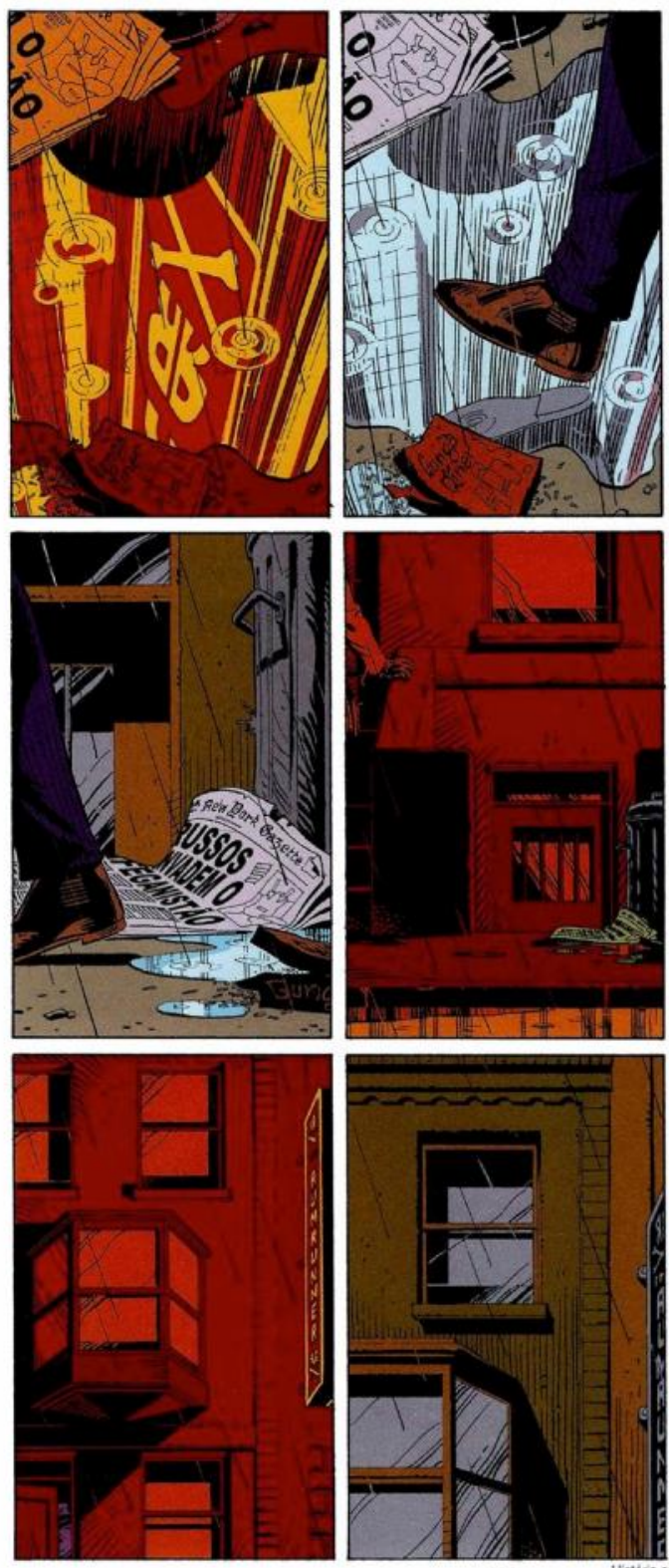

143

Fonte: MOORE, Alan. Watchmen. São Paulo: Panini, 2008.

Watchmen exige uma leitura cuidadosa para a absorção de toda a carga simbólica presente nas suas páginas, pois seu conteúdo vai muito além de uma simples história de heróis aposentados que voltam à ativa. Para 
Mukarovsky (1988, p. 66), “[...] o signo é uma realidade sensível que se reporta a uma outra realidade que cumbe evocar." O autor ainda afirma que toda e qualquer obra de arte possui a função de transmitir uma mensagem, do seu criador para o receptor. A combinação entre a manchete do jornal e o predomínio das cores soviéticas utilizadas nas ilustrações, aliada à despreocupação do homem, demonstra o perigo iminente que pairava sobre o mundo real. Apesar disso, às pessoas só restava que mantivessem sua rotina habitual e esperassem que o pior não viesse a acontecer, mas, talvez aos olhos de Moore, assim como o homem com câncer terminal, todos estivessem fadados ao pior.

O romance gráfico entrelaça-se e se confunde com a história mundial, é afetada por ela, mas também oferece uma versão alternativa em que as ações de seus personagens são causadoras de muitos desses eventos. Nesse universo alternativo, mesmo o ser mais próximo e comparável a um Deus pode ser nocivo para aqueles que o cercam; o anti-herói Comediante possui uma compreensão inigualável dos defeitos da natureza humana e, para suportar o peso desse conhecimento, faz piadas; a heroína Silhouette é assassinada por ter um defeito inaceitável para a época: o de ser lésbica. Moore criou um mundo imaginário que se alimenta diretamente da realidade mundial. Esse espaço é cínico e crítico, dotado de símbolos que expressam os mais diversos sentimentos do autor em relação ao mundo na metade século XX. Conforme Moacy Cirne (1972):

Os quadrinhos são menos simples do que aparentam: questionar o seu espaço criativo exige do crítico um sólido conhecimento dos mais diversos problemas sociais, culturais e artísticos. Este questionar o espaço criativo remete-nos para as objeções dirigidas contra a sua linguagem. É preciso saber ler formalmente os quadrinhos para que consigamos lê-los ideologicamente (CIRNE, 1972, p. 12).

Watchmen revolucionou, enfim, a cultura dos quadrinhos com seu lançamento e serve de inspiração para inúmeras outras obras. No entanto, nenhuma outra conseguiu atingir a sutileza da HQ de Alan Moore, que é um 
verdadeiro manifesto sobre as relações humanas em um mundo povoado por heróis falhos.

\section{Conclusão}

A breve análise feita nos limites deste artigo mostra que o romance gráfico, apesar de ser um gênero textual ainda recente e derivado das tradicionais HQs, teria condições de sensibilizar o leitor a se interessar por questões históricas e políticas. Nesse sentido, Watchmen, por sua qualidade gráfica e temática, poderia ser introduzido no universo escolar, de modo a ampliar o repertório de leituras literárias e não literárias dos estudantes atualmente já bastante familiarizados com o mundo das imagens.

Finalmente, por não existirem modelos ideais de análise, caberia a cada docente, de posse de uma base teórica como a que fundamenta este trabalho, elaborar e sua própria abordagem dos romances gráficos e promover a sua leitura na sala de aula. Embora pareçam simples ao primeiro olhar, os romances gráficos, como qualquer produto cultural, demandam um grande esforço de decodificação e interpretação dos signos verbais e visuais que o constituem.

\section{Referências}

BULLETIN of the Atomic Scientists. Disponivel em <http://thebulletin.org/timeline>. Acesso em: 25 nov. 2016.

CIRNE, Moacy. Quadrinhos, sedução e paixão. Petrópolis: Vozes, 2000.

CIRNE, Moacy. Para ler os quadrinhos: da narrativa cinematográfica à narrativa quadrinizada. Petrópolis: Vozes, 1972.

EISNER, Will. Quadrinhos e arte sequencial. São Paulo: Martins Fontes, 1985.

GOIDA, Hiron Cardoso; KLEINERT, André. Enciclopédia dos quadrinhos. Porto Alegre: L\&PM, 1990.

HOWE, Sean. Marvel Comics. a história secreta. São Paulo: LeYa, 2013. 
MAZUR, Dan; DANNER, Alexander. Quadrinhos: história moderna de uma arte global. São Paulo: WMF Martins Fontes, 2014.

MOORE, Alan. Watchmen. São Paulo: Panini, 2008.

MUKAROVSKY, Jan. Escritos sobre estética e semiótica da arte. Lisboa: Estampa, 1988.

TOTA, Antonio Pedro. Os Americanos. São Paulo: Contexto, 2009.

Recebido em 11 de novembro de 2016.

Aceito em 7 de dezembro de 2016. 
